\title{
The Effects of Safety Management Systems, Attitude and Commitment on
}

\section{Safety Behaviors and Performance}

\author{
Wen-Jywan Su \\ Department of Management Information System, Far East University, Taiwan \\ suwj@mail.feu.edu.tw
}

(Received July 20, 2021 Revised September 21, 2021 Accepted August 25, 2021, Available online December 1, 2021)

\begin{abstract}
Safety culture is part of organizational culture, and assessing corporate safety culture as a means of increasing safety performance is gaining acceptance. Based on Cooper's reciprocal model, this paper studied the effects of managerial safety commitment and workers' personal safety attitude as well as the organization safety management system (SMS) towards individual safety compliance and participation, and their relationship with safety performance. Questionnaires were obtained from employees and contractors of a large steel company in 14 functional departments. Modified reciprocal safety models were verified by structural equation model (SEM). The SMS and personal attitude have effects on compliance behavior. Participation behavior was influenced by the SMS and management commitment. Perceived performance was affected by compliance and participation behavior and management commitment as well. Successful implementation of a SMS will strongly motivate the workers' participation in safety activities and compliance with safety regulation. Managers' strong commitment toward safety is essential to foster safety performance. A Good safety attitude will motivate the worker to follow safety regulations for self-protection but does not encourage him to participate in safety activities. Increasing managerial safety commitment such as concerns about workers' safety participation activities and participation safety activities will directly motivate the worker's safety participation.
\end{abstract}

Keywords: Safety Culture, Safety Performance, Safety Management System, Structural Equation Model

\section{Introduction}

The beginning of connecting safety culture to accident investigation and analysis was traced to the Chernobyl nuclear accident in 1986, when the International Nuclear Safety Advisory Group (INSAG) introduced the term 'safety culture' to denote that management and organizational factors are important to safety, and since then safety culture has drawn attention of safety specialists and researchers [1]. Furthermore, the term 'safety climate' is often used in conjunction with safety culture, with little if any differentiation between the concepts.

Safety culture is part of the organizational culture, and numerous definitions of safety culture have been proposed in the safety literature, and some review papers also address the comparisons of these definitions, the definitions can be grouped into two categories - socio-anthropological and organizational psychology perspectives. Research on the role of organizational and psychosocial factors influencing risk behaviors and the likelihood of injury at work showed that safety climate (culture) has great impact [2]. Guldenmund noted the characteristics of organization culture including constructed concept, stability, multiple dimensions, shared by people and various aspects. Wiegmann et al. noted the commonalities among various definition of safety culture, including shared value within an organization, safety issues and safety management system concerns, emphasis on contributions by all members, impact on behavior at work, and contingency between reward systems and safety performance.

Assessing corporate safety culture as a means of increasing safety performance is gaining acceptance. The Baker Commission Report on the British Petroleum refinery 2005 explosion states that deficiencies in process safety culture, and management or corporate oversight, are not limited to BP, and urged companies to evaluate company safety culture regularly and thoroughly [3]. Recognizing the importance of safety culture in preventing occupational accidents has led to numerous attempts to define and assess this culture by means of different dimensionalities and combinations, and to develop valid and reliable survey questionnaire sets [4-7]. Most of safety culture questionnaires were developed in two steps, starting from a descriptive model study and then combining the results of previous 
studies. Researchers documented psychometric properties for the questionnaire, but significant shortcomings remained to the establishment of an association between safety climate/culture and safety-related outcomes.

Researchers have carried out empirical studies to determine the content of safety culture other works have reviewed these studies in an attempt to identify similar elements, but several inconsistencies are apparent, and the authors' idiosyncratic labeling of safety culture indicators make it difficult to reconcile them. Flin identified six common themes addressed in safety culture papers: i.e. management commitment, safety system, risk, work pressure, competence, and procedures/rules in their 18 review papers. And two factors, employees' involvement and management commitment to safety, have been properly replicated across all studies.

\section{Theoretical Framework}

Numerous safety culture models have been proposed. Grote and Kunzler presented a social-technical model, which is schematic but lacks means of assessment. Based on Bandura's model of reciprocal determinism, Cooper presented a reciprocal model of safety culture; this model recognizes that people (psychological), organization (situational) and behavior are key elements to form an organizational safety culture. Here 'people' refers to personal safety perception such as manager commitment and workers safety attitude; organization situation can refer to safety management system; and behavior can be related to safety performance of each individual. Neal and Griffin presented a model identifying the linkage between safety climate, safety knowledge, safety motivation and safety behavior; these authors demonstrate that safety knowledge and motivation mediate between safety climate and self-reported safety compliance and participation.

Based on Cooper's reciprocal model, and Neal and Griffin's emphasis on compliance and participation as elements of individual safety performance, this paper studied the "people" effect of managerial safety commitment and workers' personal safety attitudes and "organization" effect of the organization safety management system towards "behavior" effect of individual safety compliance and participation, and extended the relation connecting to perceived group safety performance. The proposed model is shown in Fig. 1 and hypotheses were listed as follows:

H1: The implementation of an Organization's safety management system (SMS) positively influences workers' safety compliance and safety activity participation.

H2: Personal attitude positively influences workers' safety compliance and safety activity participation.

H3: Management commitment positively influences workers' safety compliance and safety activity participation.

H4: Management commitment predicts perceived group safety performance.

H5: Workers' safety compliance and safety activity participation mediate the relationship between perceived group safety performances and antecedents (i.e. personal attitude, management commitment, and SMS).

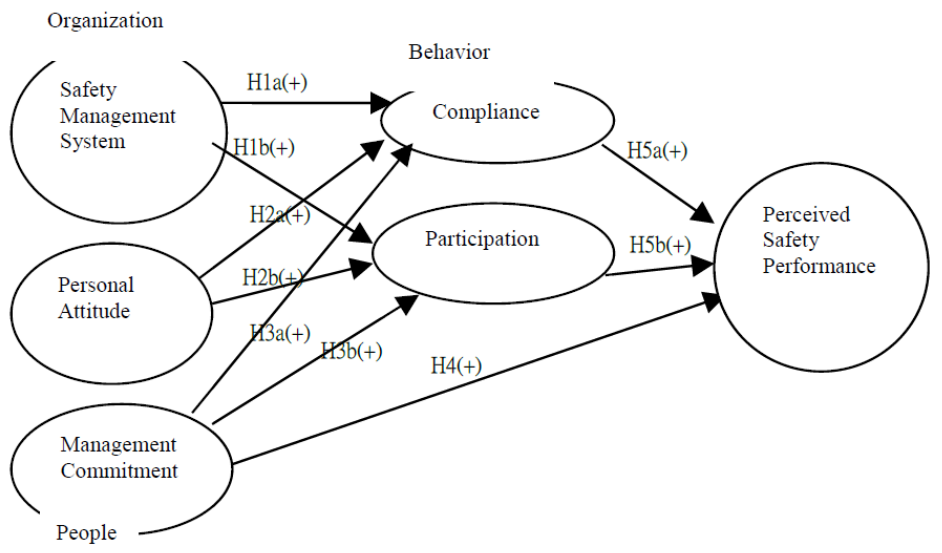

Figure. 1. Proposed model 


\section{Research Method}

\subsection{Samples}

Cooper and Phillips recommended that an organization's functional departments are the appropriate level of analysis and aggregation of individual response6, so we chose 14 different functional departments of a steel company for sampling. The samples include employee and long-term contractor workers, sampling rate is about $10 \%$ of the working population, 1379 questionnaires were distributed and 1127 valid samples were received, yielding a valid sampling rate of $81.7 \%$. Demographics of the study sample are shown in table 1. Respondents reported their degree of satisfaction with the indicators on a five point Likert scale ranging from "Strongly Disagree" (1) to "Strongly Agree' (5).

Table. 1. Demographics of study sample

\begin{tabular}{|c|c|c|c|}
\hline Variable & Item & Number & Percentage $\%$ \\
\hline \multirow[t]{2}{*}{ Gender } & Male & 1047 & 93.9 \\
\hline & Female & 68 & 6.1 \\
\hline \multirow{5}{*}{ Age } & $\sim 30$ & 147 & 13.2 \\
\hline & $31 \sim 40$ & 315 & 28.3 \\
\hline & $41 \sim 50$ & 238 & 21.3 \\
\hline & $51 \sim 60$ & 391 & 35.1 \\
\hline & $61 \sim$ & 24 & 2.2 \\
\hline \multirow[t]{5}{*}{ Position } & Management & 109 & 9.8 \\
\hline & supervisor & 275 & 24.7 \\
\hline & Engineer & 137 & 12.3 \\
\hline & $\begin{array}{l}\text { Safety } \\
\text { personnel }\end{array}$ & 103 & 9.2 \\
\hline & Operator & 491 & 44.0 \\
\hline \multirow{5}{*}{$\begin{array}{l}\text { Year of } \\
\text { working } \\
\text { experience }\end{array}$} & $\sim 1 \mathrm{y}$ & 101 & 9.1 \\
\hline & $1 \sim 2 \mathrm{y}$ & 193 & 17.3 \\
\hline & $2 \sim 5 \mathrm{y}$ & 172 & 15.4 \\
\hline & $5 \sim 10 y$ & 370 & 33.2 \\
\hline & $10 \mathrm{y} \sim$ & 279 & 25.0 \\
\hline
\end{tabular}

\subsection{Measurement Scales}

\subsubsection{Safety measurement system (SMS)}

SMS is considered as a set of integrated mechanisms in the organization, sometimes referred it as a safety program, which is designed to control the risks that may affect worker's safety and health, and many authors have stressed the 
importance of effective implementation of SMS. Previous researches have debated the contents. Fernandez-Muniz et al. listed policy, incentive, training, communication, planning and control as the six constructs to form SMS, while Guldenmund proposed SMS to contains risks, hardware design and layout, maintenance, procedures, manpower planning, competence and commitment totaling seven constructs. There are also some other proposed measurement scales for the SMS concept11, and no consensus has been reached yet.

Today, in order to pass OHSMS accreditation by international standards and guidelines [17], elements of SMS are completely formed in most big organizations, so the questionnaire on SMS is meant to survey the execution effectiveness. As safety policy is strongly related with management commitment, we consider as adequate an SMS that contains five key dimensions: risk of workplace, training, procedures, communication, incentives, and verified by second order confirmatory factor analysis.

\subsubsection{Risk at the workplace}

This variable measures the risk level of the working place, including clean up of the working environment, layout of operation machines, and safety equipment. Referred constructs in previous papers include "risk of workplace" [18] and "environment condition". Three measurement items are used.

\subsubsection{Procedure}

This variable measures the availability and usefulness of safety procedures, referred constructs in previous papers include "safety control" procedures and rules" [9]. Three measure items are used.

\subsubsection{Communication}

This variable measures the effectiveness and smoothness of transferring safety information to workers and their responses to a safety request. Referred constructs in previous studies include "communication" [19] "communication and support" [20] and "communication channel" [21]. Four measure items are used.

\subsubsection{Training}

This variable measures the existence of a training plan and how effectively safety training is related to workers' jobs. Referred constructs in previous studies include "safety training" [22] and "education and knowledge" [23]. Three measure items are used.

\subsubsection{Incentive}

This variable measures the extent to which the firm encourages workers to participate in activities for reducing risk. Referred constructs in previous studies include "incentive to participation" [19] and "S\&H encouragement and discipline" [18]. Three measure items are used.

\subsubsection{Management commitment}

This variable measures the perception of workers and supervisors to the commitment of firm's managers toward working safety. This commitment can be manifested in the positive attitude and behaviors concerning working safety. Referred constructs in previous studies include "management attitude" [22], "corporate attitude" [18] "management commitment" [24]. Four measure items are used.

\subsubsection{Personal safety attitude}

This variable measures the perception of workers or supervisors of the priority of safety in daily jobs, and the willingness to be corrected while exposed to unsafe conditions. Referred constructs in previous studies include "perceived safety priority" [7] "employee commitment" [23] "safety attitude" [5]. Three measure items are used.

\subsubsection{Determinants of safety performance}


Safety compliance and safety participation are components of workers' individual safety performance .They are concerned with determinants to group safety performance.

\subsubsection{Safety participation}

This variable measures the extent to which workers participate in activities of improving working safety and concern for co-workers' safety. Referred constructs in previous studies include "worker's involvement" and "safety participation". Four measure items are used.

\subsubsection{Safety compliance}

This variable measures the extent to which the workers abide by the firm's safety practices and to urge their co-workers to do so. Referred constructs in previous studies include "compliance with practices" [25] and "safety compliance" [26]. Three measure items are used.

\subsubsection{Perceived group safety performance}

This variable refers to the perception of safety improvement for the whole group, including the sense of working risk reduction and higher safety caring. As most workers do not have group injury rate data at hand, this measurement is quite subjective, the validity will be verified by comparison with the actual safety performance of a functional department. Referred constructs in previous studies include "dangers in workplace and accident while working" [27] and "perceived safety at work" [14]. Three measuring items are used.

\subsection{Actual Safety Performance}

Traditional measures of safety performance rely on accident and injury data, another technique is behavior sampling to see whether workers work safely or unsafely [28]. Reduction in accident and incident rates are considered to be the best result-based measure for safety culture [29], but using objective accident data to measure safety performance is notoriously problematic, and accident or injury data are insufficiently sensitive, unstable, of dubious accuracy, retrospective, and ignore risk exposure [20]. Johnson used "total recordable injury rate" (TCIR), "loss working time cases rate" (LWTCR) and "behavior \% safe" to measure group safety performance [26]. In our study, the correlation between the actual safety performance of a functional department and its measurement was studied to evaluate the validity of the measurement. Group data of "safety suggestion cases per person per year (SSR)", "OHSAS safety audit conformity rate (ACR)" and "loss of working time injury cases per million working hours (LWTCR)" from 2008-2009 were chosen to check the correlation to measurements of safety participation, safety compliance, and perceived safety performance, respectively.

\section{Results}

\subsection{Estimation of Measurement Model}

Measurement data were analyzed by statistics programs SPSS/PC version 15.0 and AMOS version 7.0 for confirmatory factor analysis (CFA). Effectiveness of the measurement model was separated into two groups: (1) the safety management system (SMS) part, including 5 constructs, workplace, procedure, training, communication and incentive (2) all the rest of the constructs, including personal attitude, management commitment, compliance, participation and perceived safety performance. The model fit results are shown in table 2. All the criteria were perfectly fitted except normed $\chi^{2}$ which was a lit bit higher than 3.0; the reason could be the big sample number.

Table. 2. Results of First Order CFA Model Fit

\begin{tabular}{|c|c|c|c|c|c|}
\hline Model Fit Index & Criteria & SMS & & $\begin{array}{l}\text { Other } \\
\text { constructs }\end{array}$ & \\
\hline & & Value & Judgment & Value & Judgment \\
\hline$\chi 2 /$ df (Normed- $\chi 2)$ & $<3.0$ & 3.43 & Fair & 3.74 & Fair \\
\hline Goodness-of-fit (GFI) & $>0.90$ & 0.966 & Good & 0.959 & Good \\
\hline
\end{tabular}




\begin{tabular}{|l|l|l|l|l|l|}
\hline Comparative fit index (CFI) & $>0.95$ & 0.981 & Good & 0.977 & Good \\
\hline Normalized fit index (NFI) & $>0.90$ & 0.973 & Good & 0.969 & Good \\
\hline Adjusted Goodness-of-fit (AGFI) & $>0.80$ & 0.950 & Good & 0.940 & Good \\
\hline $\begin{array}{l}\text { Root mean squared error of } \\
\text { approximation (RMSEA) }\end{array}$ & $<0.05$ & 0.046 & Good & 0.049 & Good \\
\hline
\end{tabular}

\subsubsection{Reliability}

The reliability study indicates the degree of internal consistency between the multiple variables which make up the scale, and represents the extent to which the indicators or items of the scale are measuring the same concepts [30]. For the purpose of guaranteeing the maximum reliability of the scales proposed, Cronbach's $\alpha$ coefficient and Composite Reliability Index were calculated for each construct. Cronbach's $\alpha$ is a coefficient that measures how well a set of items measures a single latent construct. A value greater than 0.7 is considered an adequate indication of the reliability of causal relations [30]. Bagozzi and Yi also recommend that the composite reliability index exceed minimum level of 0.631 . In table 3 and table 4, Cronbach's $\alpha$ and composite reliability index of all constructs exceed the acceptable thresholds, and thus implied adequate reliability of measurements.

\subsubsection{Construct validity}

Construct validity determines the extent to which the operation of a construct actually measures what it is designed to measure and that includes content validity, convergent validity, and discriminate validity.

\subsubsection{Content validity}

Content validity assesses the extent to which individual scale items cover the range of meanings included in the concept32. The evaluation is subjective, since it depends on the opinion of a group of experts about the procedures used in the development of the scale and about the constructs and variables that it contains. A team consisting of scholars and safety specialists was formed to review all the questionnaires, and refine the measurement after a pilot test. Further analysis was conducted to assess the psychometric properties of the measurements.

\subsubsection{Convergent validity}

The convergent validity of a concept evaluates the degree to which two measures of the same concept are correlated. Convergent validity was assessed by using standardized factor loading $(\lambda)$ between a measurement variable to the corresponding latent variable [33]. A strong condition of convergent validity is that $\lambda$ must exceed 0.5 and be significant at the $95 \%$ level. Average variance extracted (AVE) of each construct exceeds 0.5 is another supporting criterion for convergent validity [34]. All standardized factor loadings in table 3 and 4 were greater than 0.5 and loaded significantly $(\mathrm{p}<0.01)$ on its underlying construct. With the support of all constructs' AVE greater than 0.5 , convergent validity of measurements was confirmed.

\subsubsection{Discriminant validity}

Discriminant validity indicates the extent to which two conceptually similar concepts differ, and was verified by Anderson and Gerbing's methodology, which involves estimating the confidence interval of the correlation coefficient between constructs, with the aim being to ensure that no interval contains 1.0. This test is equivalent to testing the null hypothesis that the coefficient of correlation between two constructs is equal to 1.0 , so that the constructs cannot be said to be significantly distinct. In both table 3 and table 4, no any dimensional correlation confidence interval contains 1 . Construct pairs with correlation greater than 0.9 (PR-CO, CM-CP, CM-PN) was further validated by fixing the correlation at 1.0, and comparing the differences in the $\chi 2$ statistics of the constrained and unconstrained models, the results in table 5 showed significant difference. Thereby, the results provided adequate support of discriminate validity. 
Table. 3. Results of Confirmatory Factor Analysis for safety management system

\begin{tabular}{|c|c|c|c|c|c|c|c|}
\hline \multicolumn{8}{|c|}{ First order CFA for safety management system } \\
\hline $\begin{array}{l}\text { Dimension } \\
\text { variables }\end{array}$ & $\begin{array}{r}\text { Cronbac } \\
h \alpha\end{array}$ & $\begin{array}{l}\text { Composite } \\
\text { Reliability } \\
\text { Index }\end{array}$ & $\begin{array}{l}\text { Average } \\
\text { Variance } \\
\text { Extracted }\end{array}$ & $\begin{array}{l}\text { Standard } \\
\text { Factor } \\
\text { Loading } \lambda\end{array}$ & $\begin{array}{l}\text { Dimensio } \\
\mathrm{n} \text { - } \\
\text { Dimensio } \\
\mathrm{n}\end{array}$ & $\begin{array}{l}\text { Correla- } \\
\text { tion }\end{array}$ & $\begin{array}{l}\text { Confidence } \\
\text { interval of } \\
\text { corr. }\end{array}$ \\
\hline $\begin{array}{l}\text { Workplace } \\
\text { (WP) }\end{array}$ & 0.830 & 0.843 & 0.627 & & WP-PR & $0.808^{* *}$ & $0.765-0.853$ \\
\hline Place-1 & & & & $0.746^{* *}$ & WP-CO & $0.790 * *$ & $0.746-0.837$ \\
\hline Place-2 & & & & $0.826 * *$ & WP-TN & $0.717 * *$ & $0.662-0.761$ \\
\hline Place-3 & & & & $0.801^{* *}$ & WP-IC & $0.645^{* *}$ & $0.576-0.710$ \\
\hline $\begin{array}{l}\text { Procedure } \\
\text { (PR) }\end{array}$ & 0.796 & 0.792 & 0.559 & & & & \\
\hline Prodr-1 & & & & $0.734^{* *}$ & PR-CO & $0.924 * *$ & $0.875-0.965$ \\
\hline Prodr-2 & & & & $0.775^{* *}$ & PR-TN & $0.849 * *$ & $0.802-0.889$ \\
\hline Prodr-2 & & & & $0.733 * *$ & PR-IC & $0.804 * *$ & $0.730-0.862$ \\
\hline $\begin{array}{l}\text { Communic- } \\
\text { ation (CO) }\end{array}$ & 0.845 & 0.848 & 0.593 & & & & \\
\hline Com-1 & & & & $0.807^{* *}$ & CO-TN & $0.883 * *$ & $0.841-0.911$ \\
\hline Com-2 & & & & $0.735^{* *}$ & CO-IC & $0.816 * *$ & $0.765-0.863$ \\
\hline Com-3 & & & & $0.747 * *$ & & & \\
\hline Com-4 & & & & $0.763^{* *}$ & TN-IC & $0.827 * *$ & $0.782-0.862$ \\
\hline Training & 0.894 & 0907 & 0.764 & & & & \\
\hline (TN) & & 0.907 & 0.707 & & \multirow{9}{*}{\multicolumn{3}{|c|}{$\begin{array}{c}\text { Result of Model Fit: } \\
\chi^{2}(92)=315.329 \\
\text { RMSEA }=0.046 \\
\text { GFI }=0.966 \\
\text { CFI }=0.981 \\
\text { NFI }=0.973 \\
\text { AGFI }=0.950\end{array}$}} \\
\hline Tran-1 & & & & $0.914^{* *}$ & & & \\
\hline Tran-2 & & & & $0.867^{* *}$ & & & \\
\hline Tran-3 & & & & $0.840^{* *}$ & & & \\
\hline Incentive & 0.816 & 0.815 & 0.595 & & & & \\
\hline (IC) & & & & & & & \\
\hline Inc-1 & & & & $0.810^{* *}$ & & & \\
\hline Inc-2 & & & & $0.767^{* *}$ & & & \\
\hline Inc-3 & & & & $0.736 * *$ & & & \\
\hline \multicolumn{8}{|c|}{ Second order CFA for safety management system } \\
\hline $\begin{array}{l}\chi^{2}(95)=32 \\
\text { IFI }=0.980\end{array}$ & & $\mathrm{FI}=0$ & & & & & \\
\hline
\end{tabular}

Table. 4. Results of Confirmatory Factor Analysis for Commitment, Attitude, Compliance, Participation and Perceived Performance

\begin{tabular}{|c|c|c|c|c|c|c|c|}
\hline \multicolumn{8}{|c|}{ First order CFA for Conmiment, Artitude, Compliance, Participation and Perceived Safery Performance } \\
\hline $\begin{array}{l}\text { Dimension } \\
\text { variables }\end{array}$ & $\begin{array}{l}\text { Croabac } \\
\text { ha }\end{array}$ & $\begin{array}{l}\text { Composite } \\
\text { Reliabilit } \\
\text { y Index }\end{array}$ & $\begin{array}{l}\text { Average } \\
\text { Variance } \\
\text { Extracte }\end{array}$ & $\begin{array}{l}\text { Standard } \\
\text { Factor } \\
\text { Loading } 2\end{array}$ & $\begin{array}{l}\text { Dimension } \\
\text { - } \\
\text { Dimension }\end{array}$ & $\begin{array}{l}\text { Comelati } \\
\text { on }\end{array}$ & $\begin{array}{l}\text { Confidence } \\
\text { interval }\end{array}$ \\
\hline
\end{tabular}




\begin{tabular}{|c|c|c|c|c|c|c|c|}
\hline & \multicolumn{4}{|c|}{$\mathrm{d}$} & & & \\
\hline $\begin{array}{l}\text { Commitmen } \\
t(C M)\end{array}$ & 0.859 & 0.836 & 0.561 & & CM-AT & $0.670^{4 *}$ & $0.607-0.739$ \\
\hline $\mathrm{CM}-1$ & & & & $0.688^{* * t}$ & $\mathrm{CM}-\mathrm{CP}$ & $0.918^{\text {th }}$ & $0.882-0.950$ \\
\hline $\mathrm{CM}-2$ & & & & $0.729 * *$ & CM-PN & $0.965^{\text {th th }}$ & $0.933-0.997$ \\
\hline $\mathrm{CM}-3$ & & & & $0.781^{\text {*t }}$ & $\mathrm{CM}-\mathrm{pP}$ & $0.869^{\text {th }}$ & $0.825-0.909$ \\
\hline $\mathrm{CM}-4$ & & & & $0.792^{\text {** }}$ & & & \\
\hline Attitude & 0.891 & 0.822 & 0.607 & & AT-CP & $0.672^{\text {th }}$ & $0.624-0.720$ \\
\hline$(\mathrm{AT})$ & & & & & & & \\
\hline AT-1 & & & & $0.722^{\text {*t }}$ & AT-PN & $0.634^{\text {th th }}$ & $0 \not 580-0.683$ \\
\hline AT-2 & & & & $0.722^{\text {th }}$ & AT-PP & $0.567^{\text {th }}$ & $0.508-0.620$ \\
\hline AT-3 & & & & $0.839^{* *}$ & & & \\
\hline $\begin{array}{l}\text { Compliance } \\
\text { (CP) }\end{array}$ & 0.833 & 0.837 & 0.631 & & CP-PN & $0.884^{\text {th }}$ & $0.843-0.919$ \\
\hline $\begin{array}{l}\text { CP-1 } \\
\text { CP-2 }\end{array}$ & & & & $\begin{array}{l}0.751^{\text {*t }} \\
0.843^{\text {t* }}\end{array}$ & CP-PP & $0.788^{\text {th }}$ & $0.739-0.832$ \\
\hline $\mathrm{CP}-3$ & & & & $0.787^{\text {t* }}$ & PN-PP & $0.838^{\text {th }}$ & $0.787-0.875$ \\
\hline $\begin{array}{l}\text { Participation } \\
\text { (PN) }\end{array}$ & 0.862 & 0.854 & 0.595 & & & & \\
\hline PN-1 & & & & $0.709^{* * *}$ & & Result of & odel Fit: \\
\hline PN-2 & & & & $0.698^{\text {t* }}$ & & $\chi^{2}(106)=$ & 97.058 \\
\hline $\mathrm{PN}-3$ & & & & $0.848^{* 6}$ & & RMSEA $=$ & .049 \\
\hline PN-4 & & & & $0.819^{* *}$ & & $\mathrm{GFI}=0.9$ & \\
\hline Perceived & 0.891 & 0.892 & 0.733 & & & $C F I=0.9$ & \\
\hline $\begin{array}{l}\text { Performance } \\
\text { (PP) }\end{array}$ & & & & & & $\begin{array}{l}\mathrm{NFI}=0.96 \\
\mathrm{AGFI}=0 .\end{array}$ & \\
\hline Pp-1 & & & & $0.885^{\text {th }}$ & & & \\
\hline PP-2 & & & & $0.857^{\text {*t }}$ & & & \\
\hline PP-3 & & & & $0.826^{\text {t* }}$ & & & \\
\hline
\end{tabular}

Table. 5. 2 Statistic test of construct pairs of correlation greater 0.9

\begin{tabular}{|c|c|c|c|c|c|c|}
\hline $\begin{array}{l}\text { Dimension- } \\
\text { Dimension }\end{array}$ & Model & df & $\chi^{2}$ & $\Delta x^{2}$ & Criteria & Result \\
\hline \multirow[t]{2}{*}{ PR-CO } & Correlation $=1.0$ & 16 & 597.473 & \multirow[t]{2}{*}{546.687} & \multirow{6}{*}{$\begin{array}{l}\chi^{2}(3, \\
0.05) \\
=7.814\end{array}$} & \multirow{2}{*}{$\begin{array}{l}\text { Significantl } \\
\mathrm{y} \text { different }\end{array}$} \\
\hline & $\begin{array}{l}\text { Correlation } \neq \\
1.0\end{array}$ & 13 & 50.786 & & & \\
\hline \multirow[t]{2}{*}{$\mathrm{CM}-\mathrm{CP}$} & Correlation $=1.0$ & 16 & 882.041 & \multirow[t]{2}{*}{674.122} & & \multirow{2}{*}{$\begin{array}{l}\text { Significantl } \\
\mathrm{y} \text { different }\end{array}$} \\
\hline & $\begin{array}{l}\text { Correlation } \neq \\
1.0\end{array}$ & 13 & 207.920 & & & \\
\hline \multirow[t]{2}{*}{ CM-PN } & Correlation $=1.0$ & 22 & 1156.061 & \multirow[t]{2}{*}{852.426} & & \multirow{2}{*}{$\begin{array}{l}\text { Significantl } \\
\mathrm{y} \text { different }\end{array}$} \\
\hline & $\begin{array}{l}\text { Correlation } \neq \\
1.0\end{array}$ & 19 & 303.635 & & & \\
\hline
\end{tabular}

\subsubsection{Second Order CFA of Safety Management System (SMS)}

Marsh and Hacevar (1985) proposed Target Coefficient (TC) as the ratio of first order CFA $\chi^{2}$ (chi square value) to second order CFA $\chi 2$. If TC is very close to 1.0, implying a higher order latent construct existed, then a second order CFA can be a better model fit. In our case, TC $(=315.329 / 328.404=0.96)$ is very close to 1 , so we conclude workplace, procedure, communication, training and incentive could be aggregated as a second-order level of safety management system. The second order CFA of safety management system is shown in Fig. 2, with model fit index of 
normed- $\chi 2=3.46, \mathrm{RMSEA}=0.047, \mathrm{GFI}=0.963, \mathrm{CFI}=0.980, \mathrm{NFI}=0.972, \mathrm{AGFI}=0.947$, implied an acceptable model fit.

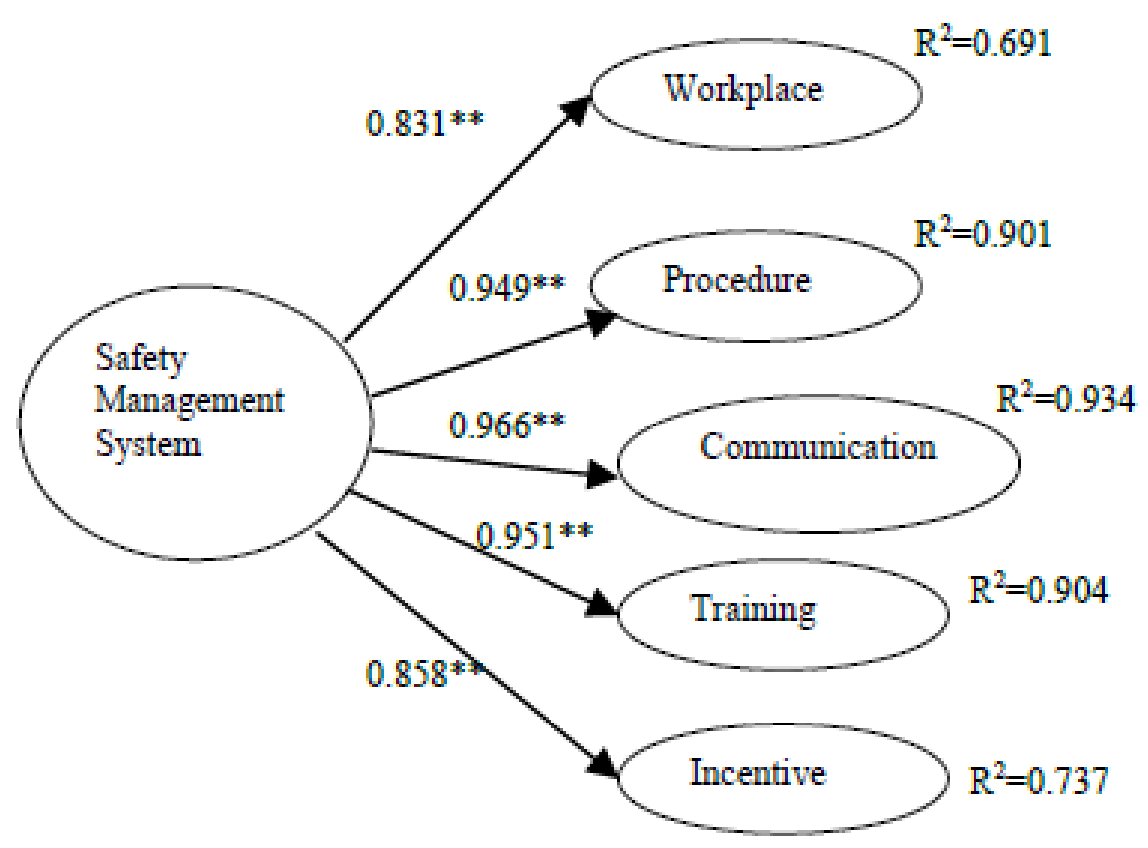

Figure. 2. Second Order CFA of Safety Management System Measurement Model

\subsection{Analysis of Structural Model}

The structured model was examined by SEM, overall model fit indices are normed $-\chi 2=3.60, \mathrm{RMSEA}=0.048, \mathrm{GFI}=$ 0.909 , CFI $=0.956$, NFI $=0.940$. Only normed $-\chi 2$ is slightly greater than 3 due to the large sample size, all others satisfy the commonly recommended threshold of respective indices. These indices suggested that the structural model fit the data adequately. Standardized path coefficients are shown as Fig. 3.

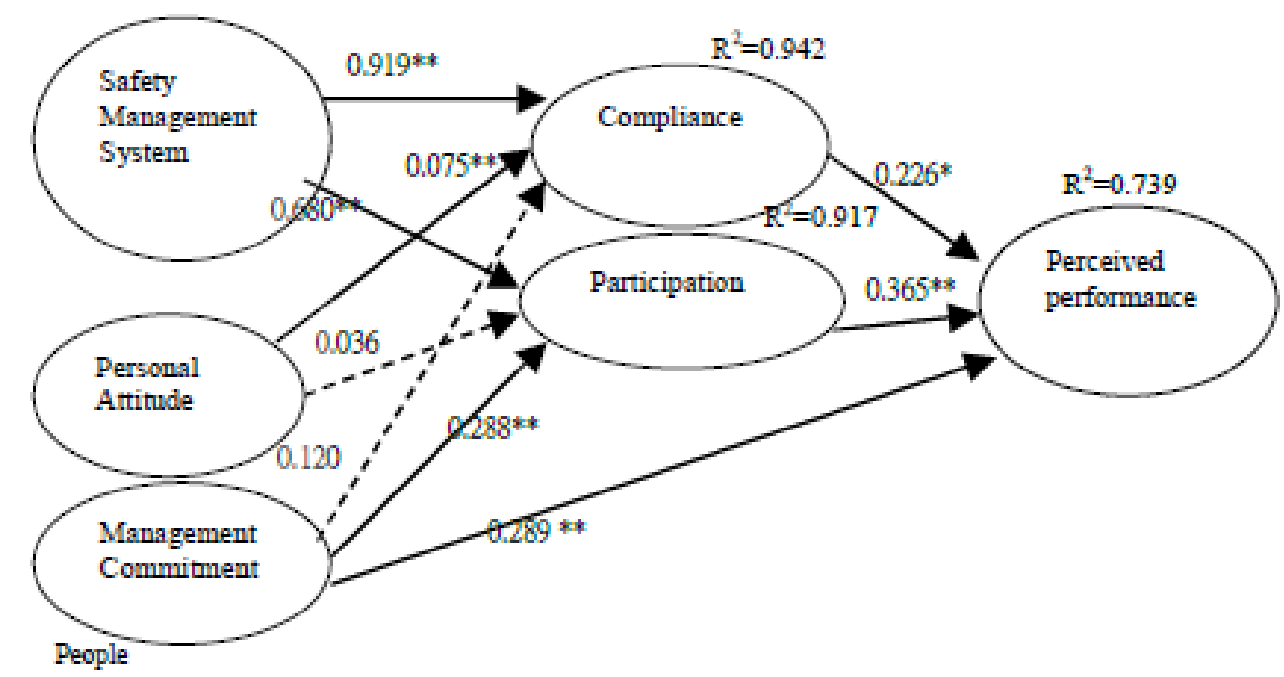

Figure. 3. Structural Model (Modified Reciprocal from SEM Analysis) 
With regards to testing the hypotheses, we got the following results:

H1: An Organization's safety management system (SMS) positively and significantly influences workers' safety compliance $(\beta=0.919, \mathrm{p}<0.01)$ and safety activity participation $(\beta=0.680, \mathrm{p}<0.01)$. Hypothesis $\mathrm{H} 1$ is fully supported.

H2: Personal safety attitude significantly influences workers' safety compliance and $(\beta=0.075, p<0.01)$, and positively $(\beta=0.036, \mathrm{p} \bullet 0.05)$ but not significantly related to safety activity participation. Hypothesis $\mathrm{H} 2$ is partially supported.

H3: Management safety commitment significantly influences workers' safety activity participation $(\beta=0.288, p<0.01)$ and positively $(\beta=0.120, \mathrm{p} \bullet 0.05)$ but not significantly related to safety compliance. Hypothesis $\mathrm{H} 3$ is only partially supported.

H4: Management safety commitment significantly predicts group safety performance $(\beta=0.289, p<0.01)$. Hypothesis H4 is supported.

H5: Workers' safety compliance $(\beta=0.226, p<0.01)$ and safety activity participation $(\beta=0.365, p<0.01)$ significantly mediate the relationship between group safety performances and antecedents. Hypothesis H5 is fully supported.

\subsubsection{Analysis of Concurrent Validity}

In order to verify the effectiveness of a questionnaire related to actual group safety performance, group averaged measurement value of compliance, participation and perceived safety performance of 14 functional departments of the target company were correlated to "safety suggestion cases per person per year (SSR)", "OHSAS safety audit conformity rate (ACR)" and "loss working time injury cases per million working hours (LWTCR)" respectively. SSR, ACR and LWTCR records were obtained from database in the target company from 2008 to 2009. This analysis provided the concurrent validity of the relations between measurements and actual safety performance. The results in table 6 showed positive and significant correlation between Compliance and ACR $(\gamma=0.600, p<0.05)$ as well as participation and SSR $(\gamma=0.768, \mathrm{p}<0.01)$. Whereas the correlation between perceived safety performances and LWTCR is -0.474 , higher injury rate will decrease the perceived safety performance as commonly understood, but correlation data is not statistically significant, the reason can be instability of LWTCR as most researchers agreed. The correlation statistics confirmed the concurrent validity of our measurements to some extent.

Table. 6. Pearson Correlation Table of averaged measurement and actual safety performance of a functional department

\begin{tabular}{|c|r|r|r|r|r|r|r|r|}
\hline & Mean & \multicolumn{1}{|c|}{$\begin{array}{c}\text { Std. } \\
\text { Dev. }\end{array}$} & A & B & C & D & E & F \\
\hline A-Compliance & 4.291 & .098 & 1 & & & & & \\
B-Participation & 4.181 & .119 & $889\left({ }^{* *}\right)$ & 1 & & & & \\
C-Perceived Performance & 4.224 & .144 & $803\left({ }^{* *}\right)$ & $.880(* *)$ & 1 & & & \\
D-Safery Suggestion Rate & .470 & .538 & $663\left({ }^{* *}\right)$ & $.768(* *)$ & $724(* *)$ & 1 & & \\
E-Audit Conformance Rate & .774 & .092 & $.600\left(^{*}\right)$ & .379 & .149 & .098 & 1 & \\
F-Loss Work Time Case Rate & .704 & .672 & $-.570(*)$ & -.369 & -.474 & -.366 & -518 & 1 \\
\hline
\end{tabular}

\section{Discussion}

Our study confirmed Cooper's reciprocal model of safety culture; manager commitment and workers' safety attitude link to people's psychological perceptions; the safety management system is able to represent the organizational situation; workers' compliance and participation together make up their behavior. The safety culture of the organization determines the safety performance of the functional department. 
In our findings, we confirmed the second order latent factor of a safety management system, which consists of training, communication, workplace risk, procedures and incentive. Successful implementation of a safety management system will strongly motivate the workers' participation in safety activities and compliance with safety regulations, and further influence the safety performance. Companies passing OHSMS accreditation will not only benefit good reputation but also ensure continuous implementation and improvement in safety, then employee safety compliance and participation will be achieved.

We also find that managers' strong commitment toward safety is essential to ensure safety performance both as a result of direct influence and indirectly through workers' safety participation. This finding agrees with many research papers showing why safety leadership is receiving higher levels of attention in many successful enterprises today $[5,19,23]$. However, management commitment is not significantly related to workers' safety compliance, that implies even if the manager talks about safety all the time, but without a systematic incentive program or communication mechanism, workers will not be swayed to comply with safety regulations.

Another finding is that workers' safety attitude is significantly connected to safety compliance, but it does not go as far as participation in safety activities. That implies good safety attitude will motivate the worker to follow safety regulations for self-protection from working hazards but it does not encourage him to care about others' safety. The atmosphere of group collective protection is relying on managerial encouragement, incentive programs and communication mechanisms.

Concurrent validity verification results showed the safety compliance and safety participation measurement in this questionnaire is significantly related to actual departmental performance determined by safety audit and safety participation activities like safety suggestion, while safety performance measurement is negatively but not significantly related to the group injuries rate record. This result gives us the confidence for using this self-evaluation questionnaire for future application for the companies without a safety activities data collection mechanism.

\section{Limitation and Future Study}

First, even though this research has covered both employees and subcontractors in fourteen functional departments, all aspects of the research were confined in one steel company and all operated under similar safety procedures, the structural model needs to be verified for every different industry sector, such as petrochemical or even a service industry. Second, while testing the concurrent validity between measurement and actual safety performance, safety suggestion cases and safety audits both have adequate quantities and are stable, so there existed significant correlation with measurement; but loss work time case rate (LWTCR) is unstable due to the low number of injury cases. We recommend that our research target company launch a Behavior Bases Safety program and collect \%safe data to be studied as a stable group safety performance index to study the predictive validity effect of our measurements in follow-up researches.

Moreover, the use of structural equation analysis does not provide evidence about causation, it only enables us to test a series of hypotheses that were consistent with causal theory, hence further longitudinal assessment is needed to provide validation of specific relationships in the model.

\section{Conclusions}

Workplace, procedure, communication, training and incentives could be aggregated as a second-order level safety management system. The Safety management system and personal attitude have effects on compliance behavior. Participation behavior was influenced by the safety management system and management commitment. Perceived performance was affected by compliance, participation behavior and management commitment as well. The correlation statistics confirmed the concurrent validity of our measurements. The reciprocal safety culture model was empirically supported by the findings of this study. This research also demonstrated that management commitment to safety, workers' personal safety attitude and implementation of a safety management system played key roles in encouraging workers' participation and compliance of safety procedures and leading to better safety performance. 


\section{Impact on Industry}

Our research not only identifies the important ingredients of safety culture, but also indicates the steps to improve safety performance. Starting from upgrading managerial safety commitment, a manager shall be concerned about workers' safety participation, safety activities, and safety training effects, personally participate in safety activities and observe workers' behavior in the workplace, frequently talk about safety in meetings and so on, in a way that will directly motivate the worker's safety participation. Second, the organization should establish and develop a safety management system and implement the system consistently. Having the SMS accredited by an outside agent based on international standards and guidelines is a good way to achieve this. Through regular audit, the system itself will enforce the organization to operate properly. The SMS shall include not only procedures for workers to comply with, but also shall have incentive program to encourage the workers to participate in safety activities like making safety suggestions, safety observation, and safety experience sharing. And safety training to enhance workers' safety attitude is also required to motivate worker to comply with safety procedures.

\section{References}

[1] Cox, S J; Flin, R., 1998. Safety Culture: Philosopher's Stone or Man of Straw?. Work \& Stress 12(3), $189-201$.

[2] Wiegmann, D. A., Hui Zhang, Douglas A. Wiegmann, Terry L. von Thaden, Gunjan Sharma and Alyssa A. Mitchell, 2002. A Synthesis Of Safety Culture And Safety Climate Research (Technical report ARL-02-3/FAA-02-2). NJ : Prepared for Federal Aviation Administration Atlantic City International Airport.

[3] Guldenmund, Frank W., 2000. The Nature of Safety Culture: A Review of Theory And Research. Safety Science $34(1), 215-257$.

[4] Ericson, James A., 2008. Corporate Culture: Examining Its Effects on Safety Performance. Professional Safety $53(11), 35-38$.

[5] Zohar, Dov, 1980. Safety Climate in Industrial Organizations: Theoretical And Applied Implication. Journal of Applied Psychology 65(1), 96-102.

[6] Cooper, Dominic M. and Robin A. Phillips, 2004. Exploratory Analysis of The Safety Climate And Safety Behavior Relationship. Journal of Safety Research 35(5), 497-512.

[7] Berends, J.J., 1996. On the Measurement of Safety Culture (unpublished graduation report). Eindhoven: Eindhoven University of Technology.

[8] Seo, Dong C., Mohammad R. Torabi, Earl H. Blair and Nancy T. Ellis, 2004. A Cross Validation of Safety Climate Scale Using Confirmatory Factor Analytic Approach. Journal of safety research 35(4), 427-445.

[9] Flin, Rhona H., Kathryn Mearns, Paul O’Connor, and Richard Bryden, 2000. Measuring Safety Climate: Identifying The Common Features. Safety Science 34(1-3), 177-192.

[10]Cox, Sue J. and Alistair J.T. Cheyne, 2000. Assessing Safety Culture in Offshore Environments. Safety Science 34(1), 111-129.

[11] Grote, Gudela and Cleiton Kunzler, 2000. Diagnosis of Safety Culture in Safety Management Audit. Safety Science 34(1-3), 131-150.

[12] Cooper, Dominic M., 2000. Towards A Model of Safety Culture. Safety Science 36(2), 111-136.

[13]Neal, Andrew and Mark A.Griffin, 2002. Safety Climate And Safety Behavior. Australian Journal of Management 27(1), 67-76.

[14]Dejoy, David M., Bryan S.Schaffer, Mark G.Wilson, Robert J.Vandenberg and Marcus M.Butts, 2004. Creating Safer Workplaces: Assessing The Determinants and Role of Safety Climate. Journal of Safety Research 35(1), $81-90$.

[15] Cox, Sue and Tom Cox, 1991. The Structure of Employee Attitude to Safety: An European Example. Work and Stress 5(2), 93-106. 
[16] Guldenmund, Frank W., 2007. The Use of Questionnaires in Safety Culture Research - an Evaluation. Safety Science 45(6), 723-743.

[17] International Labor Office, 2001. Guidelines on Occupational Safety and Health Management System. ILO-OSH 2001. Geneva: International Labor Office.

[18] Glennon, D.P., 1982. Safety climate in organizations. Proceedings of the 19th Annual Conference of the Ergonomics Society of Australia and New Zealand, 17-31.

[19]Fernandez-Muniz, Beatriz, José M. Montes-Peón and Camilo JoséVázquez-Ordás, 2007. Safety Culture: Analysis of The Causal Relationship Between Its Key Dimensions. Journal of Safety Research 38(6), 627-641.

[20] Glendon, Ian A., \& David K. Litherland, 2001. Safety Climate Factors, Group Differences And Safety Behavior in Road Construction. Safety Science 39(3), 157-188.

[21]Cabrera, D.D., Rosa Isla and Luis D. Vilela, 1997. An Evaluation of Safety Climate in Ground Handling Activities. International Aviation Safety Conference, 255-268.

[22] Cooper, M.D. and Robin A. Phillips, 1994. Validation of a safety climate measure. Occupational Psychology Conference of the British Psychological Society, Birmingham.

[23]O'Toole, Michael, 2002. The Relationship Between Employees' Perceptions of Safety And Organizational Culture. Journal of Safety Research 33(2), 231-243.

[24]DeDobbeleer, Nicole and François Béland, 1991. A Safety Climate Measure for Construction Sites. Journal of Safety Research 22(2), 97-103.

[25]Lin, Si-Hao, Wen-JuanTang, Jian-Ying Miao, Zhi-MingWang and Pei-XiWang, 2008. Safety Climate Measurement at Workplace in China: A Validity and Reliability Assessment. Safety Science 46(7), 1037-1046.

[26] Johnson, Sephen E., 2007. The Predictive Validity of Safety Climate. Journal of Safety Research 38(5), 511-521.

[27] Williamson, Ann M., Anne-Marie Feyer, David Cairns and Deborah Biancotti, 1997. The Development of A Measure of Safety Climate: The Role of Safety Perceptions And Attitudes. Safety Science 25(1-3), 15-27.

[28] Choudhry, Rafiq M., Dongping Fanga and Sherif Mohamed, 2007. The Nature of Safety Culture: A Survey of The State-of-The-Art. Safety Science 45(10), 993-1012.

[29]Clarke, Sharon, 2000. Safety Culture: Under-Specified or Overrated?. International Journal of Management Review 2(1), 65-90.

[30]Churchill, Gilbert A., 1979. A Paradigm for Developing Better Measures for Marketing Constructs. Journal of Marketing Research 16(1), 64-73.

[31] Nunnally, Jum C., 1978. Psychometric Theory. New York, NY: McGraw-Hill.

[32] Bagozzi, Richard P. and Youjae Yi, 1988. On The Evaluation of Structural Equation Model. Journal of the Academy of Marketing Science 16(1), 74-94.

[33]Hair, Joseph F. , William C. Black, Barry J. Babin and Rolph E. Anderson,1998. Multivariable Data Analysis. Upper Saddle River, NJ: Prentice Hall.

[34] Anderson, James C. and David W. Gerbing, 1988. Structural Equation Modeling in Practice: A Review And Recommend Two-Step Approach. Psychological Bulletin 103(3), 411-423.

[35]Fornell, Claes and David F. Larcker, 1981. Evaluating Structural Equation Models With Unobservable And Measurement Errors. Journal of Marketing Research 18(1), 39-50. 